Motrivivência Ano XXIII, No 36, P. 149-168 Jun./2011

doi: 10.5007/2175-8042.2011v23n36p149

\title{
CRÍTICA À REGULAMENTAÇÃO DA PROFISSÃO E À PRODUÇÃO CIENTÍFICA DEFENSORA DO SISTEMA CONFEF/CREFS
}

\author{
Guilherme Gil da Silva \\ Giovanni Felipe Ernst Frizzo ${ }^{2}$
}

\section{RESUMO}

Este texto tem por finalidade realizar a crítica à produção do conhecimento acerca da temática da regulamentação da profissão da educação física, analisando as produções científicas defensoras do Sistema Confef/Crefs, em forma de teses e dissertações publicadas no período de 1998 até 2009. Após levantamento de fontes no Banco de Teses da CAPES, foram selecionadas 14 dissertações e teses que tratam do tema, que orientam-se por posições favoráveis (que defendem o Confef/Crefs) e contrárias à regulamentação da profissão/profissional de educação física. Levantamos categorias para a análise das produções e apontamos limites filosóficos, científicos e práticos da produção do conhecimento daqueles que defendem a regulamentação da profissão.

Palavras-chave: educação física; regulamentação da profissão; produção do conhecimento

\section{Introdução}

Este texto tem por finalidade realizar a crítica à produção do conhecimento acerca da temática da regulamentação da profissão da
Educação Física (EF), analisando as produções científicas, em forma de teses e dissertações, publicadas no período de 1998 até 2009. A opção por este recorte temporal compreende o período desde a

1 Mestre em Ciências do Movimento Humano/UFRGS. Bolsista AT1 CNPq.

Contato: guilermegil@gmail.com

2 Doutorando no Programa de Pós-Graduação em Ciências do Movimento Humano/UFRGS. Bolsista CAPES. Contato: gfrizzo2@gmail.com 
aprovação da regulamentação da profissão, em forma de lei, no ano de 1998 (BRASIL, 1998b) até o ano de 2009. A opção pela análise dessas fontes parte de uma concepção de que estas representam as produções mais avançadas no campo científico, devido ao fato que são estudos realizados em programas de pós-graduação, com orientação e avaliação constituída de pesquisadores experientes, com profundo conhecimento acerca da temática desenvolvida nos estudos.

Partimos agora para a análise do fenômeno em questão e, posteriormente, apresentaremos os resultados de nosso estudo sobre a crítica à produção do conhecimento que se propõe a defender os interesses do Sistema Confef/Crefs.

\section{O fenômeno material da regu- lamentação do profissional de ef: legalidade e legitimidade}

A forma como se procedeu para a aprovação da lei e o discurso dos que a defendem mostram a busca da legitimidade pela via legalista, somente ocupando espaços institucionais e estabelecendo uma disputa entre trabalhadores. Isso só foi possível na conjuntura específica da década de 1990, a partir da Reforma Administrativa do Estado ${ }^{3}$. O seu histórico remonta-nos à década de 1940 (MARINHO, 2005), e nele é possível identificar o aprofundamento do antagonismo de classes até o processo que acabou culminando em 1998, com a aprovação de uma lei que surpreendeu toda uma área (CASTELLANI FILHO, 2002, p.86; NOZAKI, 2004, p.199). Para buscar essa legitimidade, também foi preciso forjar uma ideologia hegemônica segundo a qual os trabalhadores devem incorporar e reproduzir o modo de vida que o capital necessita, atendendo à retórica do Confef/Crefs (GAWRYSZEWSKI, 2008). É nesse plano que opera o papel da produção científica que, na defesa do projeto histórico capitalista, realiza estudos com a intenção de "naturalizar" o fenômeno da regulamentação propagandeando os supostos benefícios trazidos aos profissionais de EF, daí a relevância da presente pesquisa, que procura contrapor essa lógica.

Já no ano de 1996 - anterior, portanto, à lei 9696/98 - dois pesquisadores apontavam tendências sobre o que seria o futuro dos professores de Educação Física: ser transformados em propriedade

3 Procedida através da Lei 9649/98 (BRASIL, 1998a), aprovada no dia 27 de Maio de 1998. Note-se que apenas três meses depois foi aprovada a lei que regulamenta a profissão da $\mathrm{EF}-\mathrm{em} 1 .^{\circ} \mathrm{de}$ Setembro de 1998. 
privada ao vender sua força de trabalho (PALAFOX; TERRA, 1996, p.4). Adiante, referindo-se ao livro Profissional de educação física... existe?, de Jorge Steinhilber (1996), questionam sua rigorosidade no trato com a ciência. Segundo os críticos, Steinhilber realiza interpretações ideologicamente ingênuas e com uma visão reduzida da realidade, sendo que mencionam ter tratado disso com o próprio autor. Nas suas palavras,

[...] tivemos a oportunidade de debater com o Professor Jorge, o conteúdo de seu livro. Nessa oportunidade, mencionamos a ele, que a análise do seu conteúdo tinha sido pautada num estudo de caráter filosófico, pois seu trabalho, por ter tratado de temas relacionados com conceitos da área e as diferentes manifestações que dão sentido e significado a seu nome (Educação Física), denotavam também, implícita ou explicitamente, uma determinada concepção de homem, mundo e sociedade.

Assim, perguntamos, porque o conteúdo de seu livro não apresentou a devida fundamentação no que diz respeito à necessidade de discutir a questão com o rigor científico que o tema merece, principalmente para não incorrer no erro, que de fato aconteceu, de realizar interpretações providas de uma ideologia ingênua e reducionista da realidade, como produto da manipulação de informação sem utilização de procedimentos metodológicos que existem para isso. Estaria faltando uma adequada orientação filosófica e metodológica do tema? (PALAFOX; TERRA, 1996, p.3) [grifos nossos].

A propósito, também é interessante notar, da parte de outro crítico da postura steihilberiana, o modo como se legitima, por força simbólica, a lógica confefiana:

[...] Jorge Steinhilber contou que encontrara recentemente com seu pai, que há muito não via, e que este ficou espantado quando observou a vestimenta do filho: desde sempre insensível aos pedidos paternos para que vestisse terno e gravata, Steinhilber agora utiliza-o diariamente. [...] Desta perspectiva, pode-se dizer que, se não inaugura, o fenômeno da regulamentação dá uma nova amplitude e significação para o uso do terno e gravata no campo da EF. Incomum no habitus da EF (como mostra o exemplo de Steinhilber), a incorporação desta nova imagem pelos palestrantes pró-regulamentação e, 
depois, pelos conselheiros tem implicações tanto na economia de convencimentos quanto na posterior reordenação do campo. [...] incorporou-se a aparência e o mise en scène característicos dos homens de decisão da sociedade moderna ocidental (advogados, governantes, parlamentares, empresários): terno e gravata, pasta, laptop, manuseio de papéis, fala polida etc. (SAUTCHUK, 2003, p.186) [grifos do autor].

Vê-se, com os elementos trazidos acima, que algumas questões estão em foco há bastante tempo para confrontar a lógica confefiana, mas ainda assim persiste uma ideia equivocada sobre a sua costrução como força política na EF brasileira. Constatada a postura cientificamente ingênua pelos autores na análise do livro do atual presidente do Confef, é necessário que se diga que não são nada ingênuas as posturas políticas da entidade por ele presidida, já que, tal como os críticos mesmos se referem, refletem concepções de projeto histórico, homem, Educação Física, etc. Como é possível a um grupo tão conservador e retrógrado (CASTELLANI FILHO, 2002) na Educação Física brasileira formular as políticas de um conselho profissional? $\mathrm{O}$ que a produção do conhecimento na EF posterior a este livro argumenta em favor da perspectiva confefiana? São questões que pontuaremos a seguir.

\section{Procedimentos metodológi- cos do estudo}

Para a realização desse estudo, nos valemos no Banco de Teses da Coordenação de Aperfeiçoamento de Pessoal de Nível Superior (CAPES), entre os anos de 1998 e 2009. Assim, procurando reunir a produção científica acerca do tema de pesquisa, usamos os descritores "regulamentação" e "educação física", em sequência, para a busca ${ }^{4}$.

Foram encontradas, assim, 50 dissertações e teses, das quais, a partir da leitura dos seus resumos, 14 foram selecionadas como as que interessavam para a nossa discussão (desconsiderando as que não tocam a EF). Depois disso, ainda levantamos aquelas que orientam-se por posições favoráveis (que defendem o Confef/Crefs) e contrárias à regulamentação da profissão/profissional de EF. Abaixo, organizamos um quadro para expor as pesquisas com as quais lidamos no nosso estudo.

4 Além dos descritores "regulamentação" e "educação física", realizamos uma busca posterior com o descritor "confef", a fim de averiguar se haveria mais estudos que dissessem respeito ao tema. Isso ampliou em mais duas dissertações a busca com os descritores iniciais. 
Ano XXIII, n 36 , junho/2011

Quadro 1. Dissertações e Teses sobre o tema da regulamentação da EF.

\begin{tabular}{|c|c|c|c|c|c|}
\hline & TíTULO & AUTOR/A & $\begin{array}{l}\text { ANO E } \\
\text { NÍVEL }\end{array}$ & $\begin{array}{l}\text { INSTITUIÇÃO } \\
\text { E ÁREA }\end{array}$ & POSIÇÃO \\
\hline 1 & $\begin{array}{c}\text { A educação física e } \\
\text { a regulamentação da } \\
\text { profissão sob um olhar } \\
\text { jurídico }\end{array}$ & $\begin{array}{l}\text { Elza Miranda } \\
\text { Schmidt }\end{array}$ & $\begin{array}{c}2001 \\
\text { Mestrado }\end{array}$ & $\begin{array}{c}\text { UFU } \\
\text { (Educação) }\end{array}$ & Não definido \\
\hline 2 & $\begin{array}{c}\text { Código de ética } \\
\text { profissional de educação } \\
\text { física: analisando adesão e } \\
\text { aplicabilidade }\end{array}$ & $\begin{array}{l}\text { Ana Flávia } \\
\text { Paes Leme de } \\
\text { Almeida }\end{array}$ & $\begin{array}{c}2002 \\
\text { Mestrado }\end{array}$ & $\begin{array}{l}\text { UGF (Educação } \\
\text { Física) }\end{array}$ & $\begin{array}{l}\text { Favorável à } \\
\text { regulamentação }\end{array}$ \\
\hline 3 & $\begin{array}{c}\text { As competências } \\
\text { específicas do profissional } \\
\text { de educação física: um } \\
\text { estudo delphi }\end{array}$ & $\begin{array}{l}\text { Wallacy } \\
\text { Milton do } \\
\text { Nascimento } \\
\text { Feitosa } \\
\end{array}$ & $\begin{array}{c}2002 \\
\text { Mestrado }\end{array}$ & $\begin{array}{l}\text { UFSC } \\
\text { (Educação } \\
\text { Física) }\end{array}$ & $\begin{array}{l}\text { Favorável à } \\
\text { regulamentação }\end{array}$ \\
\hline 4 & $\begin{array}{l}\text { O judô: perspectiva com } \\
\text { a regulamentação da } \\
\text { profissão de educação física }\end{array}$ & $\begin{array}{l}\text { Alexandre } \\
\text { Janota Drigo }\end{array}$ & $\begin{array}{c}2002 \\
\text { Mestrado }\end{array}$ & $\begin{array}{c}\text { UNESP/Rio } \\
\text { Claro (Ciências } \\
\text { da Motricidade) } \\
\end{array}$ & $\begin{array}{l}\text { Favorável à } \\
\text { regulamentação }\end{array}$ \\
\hline 5 & $\begin{array}{c}\text { Educação Física e } \\
\text { reordenamento no mundo } \\
\text { do trabalho: mediações } \\
\text { da regulamentação da } \\
\text { profissão } \\
\end{array}$ & $\begin{array}{l}\text { Hajime } \\
\text { Takeuchi } \\
\text { Nozaki }\end{array}$ & $\begin{array}{c}2004 \\
\text { Doutorado }\end{array}$ & UFF (Educação) & $\begin{array}{l}\text { Contrário à } \\
\text { regulamentação }\end{array}$ \\
\hline 6 & $\begin{array}{l}\text { Cenas antigas em novo } \\
\text { espetáculo: o processo } \\
\text { de regulamentação da } \\
\text { profissão de educação física }\end{array}$ & $\begin{array}{l}\text { Maria Eleni } \\
\text { Henrique da } \\
\quad \text { Silva }\end{array}$ & $\begin{array}{c}2005 \\
\text { Mestrado }\end{array}$ & UFC (Educação) & $\begin{array}{l}\text { Favorável à } \\
\text { regulamentação }\end{array}$ \\
\hline 7 & $\begin{array}{c}\text { A reorganização da } \\
\text { formação profissional } \\
\text { em educação física no } \\
\text { Brasil: aspectos históricos } \\
\text { significativos }\end{array}$ & $\begin{array}{l}\text { Margareth } \\
\text { Anderáos }\end{array}$ & $\begin{array}{c}2005 \\
\text { Doutorado }\end{array}$ & $\begin{array}{l}\text { UNICAMP } \\
\text { (Educação } \\
\text { Física) }\end{array}$ & $\begin{array}{l}\text { Favorável à } \\
\text { regulamentação }\end{array}$ \\
\hline 8 & $\begin{array}{c}\text { Interesses e disputas no } \\
\text { processo de formulação } \\
\text { das diretrizes curriculares } \\
\text { nacionais para os cursos de } \\
\text { graduação em educação } \\
\text { física: as configurações das } \\
\text { relações pessoais }\end{array}$ & Márcia Birk & $\begin{array}{c}2006 \\
\text { Mestrado }\end{array}$ & $\begin{array}{l}\text { UFRGS } \\
\text { (Ciências do } \\
\text { Movimento } \\
\text { Humano) }\end{array}$ & Não definido \\
\hline 9 & $\begin{array}{c}\text { Sistema Confef/Crefs: } \\
\text { a expressão do projeto } \\
\text { dominante de formação } \\
\text { humana } \\
\end{array}$ & $\begin{array}{l}\text { Adriana } \\
\text { Machado } \\
\text { Penna }\end{array}$ & $\begin{array}{c}2006 \\
\text { Mestrado }\end{array}$ & UFF (Educação) & $\begin{array}{l}\text { Contrário à } \\
\text { regulamentação }\end{array}$ \\
\hline 10 & $\begin{array}{c}\text { Capoeira, trabalho e } \\
\text { educação }\end{array}$ & $\begin{array}{c}\text { Neuber Leite } \\
\text { Costa }\end{array}$ & $\begin{array}{c}2007 \\
\text { Mestrado } \\
\end{array}$ & $\begin{array}{c}\text { UFBA } \\
\text { (Educação) } \\
\end{array}$ & $\begin{array}{c}\text { Contrário à } \\
\text { regulamentação }\end{array}$ \\
\hline 11 & $\begin{array}{l}\text { Profissional ou professor } \\
\text { de educação física? } \\
\text { interfaces de uma } \\
\text { profissão regulamentada }\end{array}$ & $\begin{array}{l}\text { Ana Flávia } \\
\text { Souza Sofiste }\end{array}$ & $\begin{array}{c}2007 \\
\text { Mestrado }\end{array}$ & $\begin{array}{c}\text { PUC/SP } \\
\text { (Educação) }\end{array}$ & Não definido \\
\hline 12 & $\begin{array}{l}\text { CONFEF: organizador da } \\
\text { mercantilização do campo } \\
\text { da Educação Física }\end{array}$ & $\begin{array}{c}\text { Bruno } \\
\text { Gawryszewski }\end{array}$ & $\begin{array}{c}2008 \\
\text { Mestrado }\end{array}$ & $\begin{array}{c}\text { UFRJ } \\
\text { (Educação) }\end{array}$ & $\begin{array}{l}\text { Contrário à } \\
\text { regulamentação }\end{array}$ \\
\hline
\end{tabular}

5 Definimos esta posição a partir do fato que a autora foi representante do Confef/Crefs, tendo sido eleita conselheira efetiva do Cref5/CE-MA-PI entre os anos de 2005 e 2006. 


\begin{tabular}{|c|c|c|c|c|c|}
\hline & TíTULO & AUTOR/A & $\begin{array}{l}\text { ANO E } \\
\text { NÍVEL }\end{array}$ & $\begin{array}{c}\text { INSTITUIÇÃO } \\
\text { E ÁREA }\end{array}$ & POSIÇÃO \\
\hline 13 & $\begin{array}{c}\text { O reordenamento no } \\
\text { mundo do trabalho e a } \\
\text { precarização do trabalho } \\
\text { do professor de educação } \\
\text { física: mediações da } \\
\text { mercadorização da cultura } \\
\text { corporal }\end{array}$ & $\begin{array}{l}\text { Tatiane } \\
\text { Carneiro } \\
\text { Coimbra }\end{array}$ & $\begin{array}{c}2009 \\
\text { Mestrado }\end{array}$ & UFF (Educação) & $\begin{array}{l}\text { Contrário à } \\
\text { regulamentação }\end{array}$ \\
\hline 14 & $\begin{array}{l}\text { Formação em educação } \\
\text { física: uma análise à luz da } \\
\text { centralidade do trabalho }\end{array}$ & $\begin{array}{c}\text { José Pereira } \\
\text { de Sousa } \\
\text { Sobrinho }\end{array}$ & $\begin{array}{c}2009 \\
\text { Mestrado }\end{array}$ & UFC (Educação) & $\begin{array}{l}\text { Contrário à } \\
\text { regulamentação }\end{array}$ \\
\hline
\end{tabular}

Em síntese, a partir das informações do quadro acima, vemos que há duas teses e 12 dissertações. Aproximadamente um terço das produções (cinco entre 14) realiza a defesa da lógica confefiana, seis são contrárias e outras três não conseguimos ter uma definição clara ${ }^{6}$. A instituição que reúne maior quantidade de produções é a UFF (3), seguida pela UFC (2) e pelas demais (1) - PUC-SP, UGF, UFBA, UFRGS, UFRJ, UFSC, UFU, UNESP, UNICAMP - sendo que cinco entre todas elas foram defendidas no Estado do Rio de Janeiro (UFF, UFRJ e $\left(\mathrm{UFF}^{7}\right.$. São três as produções no ano de 2002, duas nos anos de 2005, 2006, 2007 e 2009 e uma nos anos de 2001, 2004 e 2008, sendo que no ano de 2003 não há produções. Não há produções entre os anos de 1998 e 2001. Apenas cinco produções se localizam na área da Educação Física ${ }^{8}$, sendo as demais vinculadas à área da Educação.

Por fim, de posse desse quadro, estabelecemos como critério para a realização da crítica no presente artigo a utilização apenas daquelas que pudemos acessar na íntegra, ou seja, que estivessem disponíveis como documento completo (não apenas em resumo) em meio virtual para consulta. Assim, a crítica sobre a produção científica defensora do Confef/Crefs é feita a três monografias (ALMEIDA, 2002; FEITOSA, 2002; ANDERÁOS, 2005), de onde levantamos categorias para a análise das produções.

Numa visão geral, esses três estudos se caracterizam como pesquisas quantitativas, com a utilização de

6 Também é interessante referir que a maioria (53\%) dos artigos sobre o tema publicados na Revista Brasileira de Ciências do Esporte mostra-se contrária ao Confef/Crefs (SOFISTE, 2007, p.17-18).

7 Não nos ateremos a este fato, mas trata-se do Estado onde se localiza a sede do Confef e onde se dão, por isso, os maiores embates entre este e os trabalhadores da EF.

8 Incluindo as que se vinculam a programas de Ciências do Movimento Humano e de Ciências da Motricidade. 
métodos estatísticos para verificação de suas hipóteses. Os autores trabalham em um viés empíricoanalítico, cujo entendimento de ciência está vinculado a princípios de quantificação e matematização dos fenômenos, de análise e descrição segundo parâmetros estatísticos, de a-historicidade do objeto, de alusão à "imparcialidade" e "neutralidade" do pesquisador, entre outros aspectos, que indicam uma concepção de ciência alicerçada em pressupostos positivistas (TRIVIÑOS, 1987). Outro fator que é bastante significativo é o fato de que nos três estudos o/a autor/a ou o orientador estavam (ou ainda estão) diretamente vinculados ao Confef/Crefs, respondendo por cargos de conselheiros ou compondo alguma de suas comissões, como poderemos ver a seguir.

\section{Estudo I: Almeida (2002)}

Sob o título: Código de Ética Profissional de Educação Física: analisando adesão e aplicabilidade, o estudo orientado pelo Prof. Dr. Lamartine Pereira da Costa (atualmente conselheiro do Confef), foi defendido no ano de 2002 por Ana Flávia Paes Leme de Almeida. Já se percebe desde o título que se trata de um instrumento de propaganda e divulgação do Confef/Crefs, especificamente da efetividade do seu código de ética. Para ilustrar essa afirmação, basta observarmos um dos objetivos do estudo: "verificar a ocorrência e o processo de desenvolvimento ou de inibição de três condições básicas para a aplicação do Código de Ética Profissional de Educação Física, definidas preliminarmente como fácil compreensão, fácil acesso e aplicação prática na profissão" (ALMEIDA, 2002, p.22). A autora estuda se o código de ética do Confef está sendo respeitado, cumprido e se os profissionais sabem de sua existência para praticar o que apregoa o Confef/Crefs. E segue, ainda, com a refutação de qualquer outra perspectiva de discussão acerca da regulamentação da profissão, impregnada de uma visão legalista:

[...] entendo que a discussão do projeto que tramitou no Congresso e o processo de discussão e aprovação da referida lei 9696/98, atualmente em vigor, estão superados, pois o grupo que conseguiu passar esta proposta é aquele que conseguiu implementar a sua visão aos legisladores e aos profissionais da área que auxiliaram na aprovação desta nova legislação. Em síntese, há um fato indiscutível sob o ponto de vista da legalidade: a profissão de Educação Física hoje é Regulamentada e já é elevado o número de registrados em todo o país (ALMEIDA, 2002, p. 48-49) [grifo nosso]. 
Ou seja, nesta visão, o fato de algo tornar-se lei significa que está superada qualquer discussão contrária, inclusive significa que a lei estabelece quem é "vencedor" das discussões. Além da adesão política e ideológica da autora ao Confef/Crefs, ela recebeu apoio financeiro do mesmo para a realização do estudo, como podemos perceber quando explica sobre a distribuiçãa dos questionários aos participantes da pesquisa:

A distribuição do questionário foi feita via correio, dentro do jornal do CONFEF e respondido pelo sistema de carta resposta, com selo pré-pago. Os selos foram pagos pelo CONFEF. Foram distribuídos 5641 questionários, número este relativo ao total de registrados no CREF-01 (Rio de Janeiro e Espírito Santo) na época (ALMEIDA, 2002, p.62-63) [grifos nossos].

Este é um ponto que suscita diversos questionamentos, principalmente pelo fato de ser um estudo que se propõe a discutir a ética do Confef/Crefs e, ao mesmo tempo, se atrela a tal entidade que propõe um código de ética cuja matéria foi tema de diversas críticas na produção científica, como nos estudos de Nozaki (2004), Sofiste (2007), Gawryszewski (2008). Para expressar essa carência de rigor ético e científico do estudo, basta questionarmos: se o Confef/Crefs financia esse estudo, qual a possibilidade da autora efetivar alguma análise crítica à ética do Confef ou à regulamentação da profissão? Parece-nos que nenhuma.

Ao realizar esse estudo, a autora também tem por preocupação melhorar os procedimentos realizados pelo Confef/Crefs. Primeiro, ao afirmar que o seu trabalho "implica em classificar a presente pesquisa como aplicada, uma vez que seus resultados servirão potencialmente de base para futuras reformas nos procedimentos do Confef e seus segmentos Regionais" (ALMEIDA, 2002, p.23). Em outro momento, a autora expressa: "se conseguirmos identificar o perfil dos profissionais vinculados ao Conselho, assim como sua relação e compreensão do Código de Ética, poderemos direcionar futuros procedimentos. Com isso, poder-se-á evitar que o Código torne-se mais um instrumento burocrático sem aplicabilidade" (ALMEIDA, 2002, p. 24).

Estudo II: Feitosa (2002)

A dissertação de Wallacy Milton do Nascimento Feitosa (2002) tem como título: As competências específicas do profissional de educação física: um estudo 
delphi, sob orientação do Prof. Dr. Juarez Vieira do Nascimento, à época membro da diretoria do Cref3/SC na Comissão de Ensino Superior. $\mathrm{O}$ autor não realiza um estudo para propagandear as realizações do Confef/Crefs, embora não expresse nenhuma crítica à questão da regulamentação da profissão e argumente que a lei 9696/98 tenha sido "necessária como facilitadora para a definição das novas ocupações da profissão de Educação Física" (FEITOSA, 2002, p.4). O autor trata de duas questões centrais, o mercado de trabalho e as competências necessárias para o professor de EF atuar nele. Na discussão sobre o mercado é feita uma relação entre a formação do professor de EF e o que se espera de sua atuação, estabelecendo uma relação direta entre esses elementos. Ao trabalhar com as competências, as principais referências são aquelas conhecidas como a "pedagogia das competências", ou seja, o professor (ou o profissional) deve desempenhar seu trabalho baseado nas competências exigidas pelo mercado de trabalho. Isso fica bastante claro ao definir o problema de sua dissertação:

\section{[...] quais são as competências} específicas necessárias para o desempenho do profissional de Educação Física nas áreas de atuação da Docência em
Educação Física no Ensino Fundamental e Médio, Treinadores Esportivos das diversas modalidades e Orientadores de Atividades Físicas para grupos e indivíduos? (FEITOSA, 2002, p. 3) [grifo nosso].

No desenvolvimento de seu estudo, o autor trata dos requisitos necessários para ser um "profissional competente" no mercado de trabalho, ao sugerir que: "o profissional competente precise dominar conhecimentos técnicos relativos às exigências da sua clientela" (FEITOSA, 2002, p.39). No estudo, o autor também faz menção à pretendida "certificação" que a regulamentação da profissão cria através do registro no Cref, como se fosse esse um critério de competência e ética profissionais.

Estudo III: Anderáos (2005)

A tese desenvolvida por Margareth Anderáos (2005) tem um alto teor panfletário, na defesa dogmática do Confef/Crefs e da regulamentação da profissão, e leva o título: A reorganização da formação profissional em educação física no Brasil: aspectos históricos significativos. Na época em que desenvolveu seu estudo de doutoramento, a autora era membro da diretoria do Cref4/SP e seu orientador - João 
Batista Andreotti Gomes Tojal - era $1 .^{\circ}$ vice-presidente do Confef (cargo que ocupa até os dias de hoje). Podemos perceber essa defesa unívoca da regulamentação da profissão em diversos momentos de sua tese, tais como ao realizar discussões acerca das ações realizadas pelo Cref4/SP, em que a autora assim se manifesta: "como membro do Conselho Regional de Educação Física da $4{ }^{a}$ Região/ $\mathrm{SP}$, apresento a seguir as ações desse órgão, as quais podem ter significado contribuições para a capacitação Profissional em Educação Física" (ANDERÁOS, 2005, p.108).

Depois disso, a autora se surpreende e coloca em dúvida o que pensam os coordenadores de curso que foram entrevistados, quando estes respondem que as ações do Confef não contribuem para a formação do professor de EF. Após a autora listar algumas atividades realizadas pelo ConseIho, ela coloca: "Questiono-me sobre o nível de informação dos coordenadores dos cursos da área. Saberiam à respeito de todas essas ações?" (ANDERÁOS, 2005, p.151). E segue fazendo juízo de valor sobre o que pensam os coordenadores dos cursos de EF:

[...] 4 coordenadores desconhecem as ações realizadas pelo Conselho Federal de Educação Física, como facilitadoras da meIhoria na formação profissional.
Não posso afirmar com segurança que desconhecem as ações ou que não reconhecem que valorizar a profissão, meIhorar a auto estima dos profissionais, tornar o mercado de trabalho mais exigente possibilitará a curto e médio prazos, uma capacitação da formação profissional (ANDERÁOS, 2005, p.151-152) [grifo nosso].

Acusa-os de não ter responsabilidade ética para a coordenação dos cursos de EF, ao afirmar o

[...] fato do Coordenador não estar presente no momento histórico da alteração referida no questionário não se justifica, já que considero que um Coordenador tem por obrigação ética conhecer a história do Curso que coordena, para entender todo o desenrolar histórico processado ao longo do tempo que, inclusive explica a situação vivida no momento atual (ANDERÁOS, 2005, p.140) [grifos da autora].

E, por fim, a autora conclui a defesa da regulamentação da profissão com generalizações de qualquer natureza que, para nós, não condizem com a realidade: "as ações políticas emanadas pelo Sistema contribuíram para elevar a autoestima dos profissionais que estão reconhecendo que as atividades características das 
suas ações profissionais estão sendo mais valorizadas pela sociedade, que exigirá qualidade nos serviços prestados" (ANDERÁOS, 2005, p.167).

\section{A defesa da lógica confefia- na: buscando categorias de análise}

Após alguns apontamentos sobre os trabalhos em questão, pudemos estabelecer duas categorias centrais que expressam a lógica confefiana: 1) formação para o mercado de trabalho - os autores têm por entendimento que o mercado de trabalho deve ser o regulador e o parâmetro que baliza a formação do professor de EF; 2) concepção de profissional na lógica do capital - o trabalhador deve adequar-se acriticamente às exigências demandadas pelo mercado de trabalho para exercer a sua profissão de maneira "competente, ética e eficaz".

Formação profissional: a lógica do mercado de trabalho

A discussão acerca da formação de professores de EF é cada vez mais atual e se renova a cada movimentação no plano da legislação ou nas disputas políticas que partem de diferentes perspectivas de ser humano, história e sociedade. Nesse bojo de disputas se encontram aqueles que defendem a perspectiva de formação humana a partir da omnilateralidade, como um processo de formação que não se subsume ao mercado como parâmetro regulador da formação do professore de EF; e, por outro lado, está uma posição que defende a formação profissional atrelada à lógica de mercado, baseada na pedagogia das competências e na teoria do capital humano.

É nessa última perspectiva que se estabelecem as Diretrizes Curriculares Nacionais (DCN's) para os cursos de graduação em EF (BRASIL, 2004), com a interferência direta do Confef garantindo os seus próprios interesses (os interesses do capital) - de atender às demandas do mercado de trabalho. A divisão do curso de EF em Licenciatura e Bacharelado representa a fragmentação do conhecimento em duas áreas distintas, forjando uma falsa dualidade (CRUZ, 2009), e pauta a formação dos professores em modismos e necessidades de "mercado", que atualmente tem apresentado condições cada vez mais precarizadas e inconstantes aos trabalhadores da EF e das manifestações da cultura corporal. Tratase de uma subordinação a interesses de grupos específicos (BIRK, 2006), em atendimento a orientações de organismos internacionais, a partir de uma lógica autoritária e imposta, 
que se explicita como mera adaptação ao marco legal.

Essa perspectiva de formação fragmentada e fundamentada na lógica de mercado pode ser observada nos estudos que analisamos, cuja origem está atrelada à ideologia confefiana, como afirmamos anteriormente. A noção de qualidade do ensino nesses estudos se fundamenta nas demandas que emergem do mercado de trabalho, sendo mais qualificado aquele que atende com mais competência e eficácia o que se exige no mercado. Essa foi uma das preocupações que Anderáos teve em seu estudo, ao analisar se as IES estão atendendo às demandas de mercado (ANDERAÓS, 2005, p. 15).

Nessa "necessária" relação da formação com o mercado, a autora vai concluir que no

[...] sentido de busca de reconhecimento do significado da participação e da intervenção especializada do profissional de Educação Física junto à sociedade é indispensável que se adotem algumas providências e uma delas é a preparação mais adequada e eficiente, que tem sido uma saída sempre buscada. No entanto, é necessário que esta se torne uma missão de todos os que atuam como Dirigentes e Docentes nos Cursos que se destinam a preparar profissionais para o mercado de trabalho específico no campo das atividades físicas, desportivas e de lazer (ANDERAÓS, 2005, p. 67) [grifo nosso].

A defesa da fragmentação da formação em licenciatura e bacharelado também é uma prerrogativa do Confef/Crefs, haja visto as suas articulações ao longo dos últimos anos para tentar convencer a comunidade acadêmica de que isso significa um avanço para a EF. Para fazer este convencimento, aqueles que defendem essa perspectiva não poupam argumentos falaciosos acerca daquilo que constitui historicamente o campo da EF. Exemplo disso se refere ao campo de atuação do licenciado e do bacharel em EF, matéria sobre a qual o Conselho Nacional de Educação (CNE) se debruçou para elaborar o Parecer CNE/CES 400/2005, no qual afirma que é inconstitucional que conselhos profissionais expeçam registros diferenciados para licenciados ou bacharéis em qualquer área. Essa decisão do CNE se fundamenta no fato de que não há impedimentos legais para o licenciado em EF atuar em qualquer campo de trabalho da $\mathrm{EF}$, diferentemente do bacharel, que não pode exercer a docência em espaços escolares. Esse entendimento parte da ideia de que todos os licenciados têm acesso 
aos conhecimentos específicos da área, além de conhecimentos pedagógicos que o permitam exercer a docência. Esse foi um dos motivos pelos quais a maior parte das universidades brasileiras, mesmo com a possibilidade de criar cursos de bacharelado desde a resolução CFE 03/1987, optaram por manter a formação em licenciatura em EF. Também é motivo dessa opção o entendimento de que a história da EF constitui o caráter pedagógico como princípio de todos os campos de trabalho do professor de EF escola, academia, clube esportivo, hospitais, etc.

É possível percebermos esses discursos falaciosos em duas questões: 1) quando buscam impedir o licenciado em EF de trabalhar no campo não-escolar; 2) quando confundem a comunidade acadêmica da EF afirmando que a licenciatura ampliada diz respeito a uma mera "junção" entre licenciatura e bacharelado em um único curso para atuar amplamente no mercado de trabalho, como afirmou Anderaós (2005)

A maioria dos Cursos de Graduação em Educação Física passou a oferecer as duas formações, Bacharelado e Licenciatura, em um único projeto integrado, mais conhecido, nessa área, por Licenciatura expandida ou ampliada, uma vez que consideram que o Licenciado possui o direito de atuar em todos os campos de trabalho possíveis, inclusive sendo especialista para atuar na escola, o que foi impedido ao Bacharel (ANDERÁOS, 2005, p.163) [grifo nosso].

A licenciatura ampliada é uma proposta elaborada pelo Movimento Estudantil da EF (MEEF) e sistematizada pelo grupo de pesquisa LEPEL/UFBA. Esta proposta de formação é ampliada porque a ela subjaz uma concepção de formação omnilateral (v. MANACORDA, 2007) (e não unilateral, na perspectiva de mercado), cuja formação profissional é apenas um dos elementos da formação humana. Essa proposta reune diversos elementos, entre eles a história como matriz científica, o trabalho como princípio educativo e o trato do conhecimento pelo sistema de complexos; portanto, não significa somente a junção de licenciatura e bacharelado em um só curso, para atuar no mercado de trabalho, mas uma outra proposta de formação, que supera por incorporação a atual. Há, portanto, um grande equívoco de ordem teórica entre aqueles, como a referida pesquisadora, que consideram a perspectiva de mera "junção" de dois currículos em um, 
tratando isto como uma formação ampliada.

Concepção de profissional: a lógica do capital

Nos estudos analisados, percebe-se que os defensores da regulamentação da profissão e do Confef/Crefs advogam em favor de uma concepção de profissional que deve se adequar às oscilações e modismos de mercado para sobreviver em meio a um período de desemprego estrutural. As principais argumentações giram em redor de pressupostos da "defesa da sociedade" contra os leigos, de questões éticas emanadas do seu código de ética e das competências que o profissional de EF deve reunir.

A argumentação de que a sociedade deve se proteger contra os "leigos" surgiu como principal motivação para a suposta necessidade de regulamentar a profissão. Afirmavam os defensores da regulamentação que havia muitos trabalhadores exercendo atividades que deveriam ser reservadas exclusivamente aos profissionais de EF (STEINHILBER, 1996). Deriva daí o primeiro questionamento à regulamentação da profissão, pois esta exerce a função de reserva de mercado, o que é uma condição inconstitucional. Anderáos (2005) infundadamente defende essa questão através de argumentos generalistas acerca do que a sociedade necessita, e expressa que a regulamentação da profissão da EF se estabeleceu "a partir de condições bastante almejadas e aguardadas por muitos profissionais da área e ao mesmo tempo questionadas por outra parcela de indivíduos que mesmo sem a necessária preparação acadêmica se serviam do mercado definido no campo de atuação dos profissionais da área" (ANDERAÓS, 2005, p.12-13).

É comum encontrarmos no discurso confefiano a caracterização da EF como sendo "uma área da saúde que oferece riscos à população quando mal orientada". Anderáos (2005) confirma esse discurso ao questionar:

se a Educação Física é importante e oferece riscos à população quando mal orientada, se os profissionais de Educação Física para que tenham o direito de atuar no mercado cursam o Ensino Superior e se preparam para o mundo do trabalho, será que essa área não necessita desses profissionais graduados e os mesmos não merecem esse tipo de reserva de mercado pela qualidade e significação daquilo que produzem e representam? (ANDERAÓS, 2005, p.13).

Observa-se nessa passagem o discurso contra os "leigos" 
e a necessidade de reserva de mercado. Porém, devemos questionar a seguinte contradição: até que ponto o Confef/Crefs realmente entende que os leigos oferecem risco à população, na medida em que "formam" provisionados e os registram, mesmo sem terem acesso ao Ensino Superior? Quem o Confef/Crefs define com "leigo" se, no texto da lei 9696/98, qualquer trabalhador que atua no ramo da "atividade física" deve ser formado em $\mathrm{EF}$ e registrado no Cref? Para Sautchuk (2003) há uma oposição "explícita e belicosa", e o autor procura compreender a produção desta distinção entre "leigo" e "profissional", forjada pelo Confef/Crefs, sintetizando sua análise em um quadro que vale a pena reproduzir abaixo:

\begin{tabular}{|c|c|}
\hline Profissional & Leigo \\
\hline segurança & perigo \\
ordem & desordem \\
transparente & obscuro \\
ética & moral duvidosa \\
qualificação & despreparo \\
especialização & diletantismo \\
conhecimento científico & saber não legítimo \\
\hline
\end{tabular}

Figura 1. reprodução de quadro sobre oposição entre "profissional" e "leigo" (SAUTCHUK, 2003, p.183).

Com relação aos "provisionados", a legislação garante que aqueles trabalhadores que comprovassem o exercício profissional na área das atividades físicas em período anterior à publicação da lei 9696/98 poderiam ter seu registro assegurado. O Confef elaborou o Programa de Instrução para Provisionados (PIP) como uma justificativa de que a instrução do provisionado seria ética, competente e eficaz. Ou seja, o "leigo", assim, está apto a exercer a profissão após realizar um curso de instrução de 200 horas, chancelado pelo Confef/Crefs. Cai por terra, portanto, o argumento de que o "leigo" deve ser impedido de trabalhar no campo das atividades físicas. Ainda que o Confef/Crefs argumente que foi "obrigado" a registrar os trabalhadores que fizessem as devidas comprovações, percebe-se que, na prática, o registro de provisionados se mantém como uma política de arrecadação (tendo em vista o custo do PIP) e também de tentar não manter uma imagem antipática junto à sociedade, ainda que isso seja realizado por cima da legislação vigente: o ex-treinador de futebol da seleção 
brasileira de futebol, por exemplo, não tem graduação em EF. Portanto, ele não poderia exercer a função de treinador de futebol, ainda mais pelo fato de que, antes da 9696/98, Dunga não era treinador, mas, sim, atleta. Porquê, então, o Confef não o impediu de ser o treinador na última copa do mundo? Exatamente pelo fato de que seguem registrando "leigos" para trabalhar na EF, através de seus cursos de provisionados realizados ilegalmente ${ }^{9}$.

Entre tantos contrassensos e contradições, a ética promovida pelo Confef/Crefs deve ser questionada, ainda mais quando analisamos os estudos e percebemos que essa ética está diretamente vinculada à produtividade das empresas e das exigências de mercado. Como afirma Almeida (2002),

A ética profissional hoje, não é vista só como uma questão de consciência, é uma crescente exigência do mercado. As empresas rejeitam profissionais que podem comprometer a imagem delas. Uma política interna mal definida por um funcionário de qualquer nível pode repercutir em dois dos maiores patrimônios de uma empresa: a marca e a imagem (ALMEIDA, 2002, p.54).
Da mesma forma, a lógica das competências está impregnada de uma objetividade adequada à logica de mercado (MARTINS, 2004), como forma de superar os demais trabalhadores que disputam o baixo número de empregos disponíveis e de aceitar a precarização do trabalho como algo "naturalmente estabelecido" e que nada pode ser feito quanto a isso. Essa noção de competência foi assim definida por Feitosa (2002, p.30), como o conjunto de conhecimentos, habilidades e atitudes necessárias para uma atuação profissional "adequada". Perguntaríamos: adequada a quê? A própria autora de um dos estudos que analisamos afirma isso da seguinte forma:

[...] pela própria organização da política neoliberal que organiza nosso setor político, econômico e de serviços sociais como a saúde e a educação, conjuntamente com a problemática advinda desse novo modo de organização, justifica-se a necessidade de um órgão como os ConseIhos profissionais para que fiscalizem o exercício profissional, principalmente da área da saúde, que é o bem maior que um ser humano pode possuir (ANDERÁOS, 2005, p.102).

9 É possível acessar o registro de Dunga no site do Confef: CREF 011848-P/RS. Outros casos também podem ser acompanhados até mesmo pelos meios de divulgação do Confef/Crefs (cf. EF, 2008, p.31). 
Esse atendimento às demandas do mercado, como se essas fossem a única possibilidade de trabalho que a humanidade já produziu, junto ao fato de que a precarização do trabalho e o desemprego são questões de adaptação por parte do profissional ético, competente e eficaz, não são propagadas pelos representantes do Confef/Crefs ingenuamente, mas como uma posição referente ao projeto histórico defendido por eles, em que a criação dos conselhos profissionais como instrumentos de caráter privado para controlar e fiscalizar o trabalhador atende perfeitamente às demandas da forma capitalista de organizar a vida.

\section{Considerações Finais}

Outros estudos que abarquem a produção científica expressa em artigos de periódicos, além das dissertações e teses, são necessários. Nossos argumentos fazem a crítica aos defensores da regulamentação da profissão e do profissional de EF, tendo em vista que esse fenômeno aprofunda o antagonismo de classes existente em nossa sociedade, justamente por colocar de um lado aqueles que têm interesses privados e corporativistas cabíveis a um contexto de regulação da vida pelo mercado e, de outro, os professores de EF que lutam por melhores condições de trabalho em meio a um contexto de crise estrutural do capitalismo e de precarização do trabalho. Nossa crítica é científica, no sentido de que nos debruçamos sobre matéria que já ocupa uma série de trabalhos monográficos no Brasil; mas, além disso, nossa crítica também é política, exatamente porque a ciência não está cindida desse aspecto e expressa os interesses de determinado projeto histórico, ou seja, não há neutralidade científica na análise dos fenômenos da realidade, sejam eles naturais ou sociais.

É possível, pelo que foi tratado até aqui, identificar com certa clareza na produção científica da EF aqueles estudos que defendem e os que se colocam contrários à regulamentação da profissão. Entre os que a defendem, nitidamente uma minoria da produção encontrada, apontamos limites de ordem científica, centralmente tendo por referência duas categorias - formação profissional e concepção de profissional. Tais limites, é possível dizer, refletem uma perspectiva já adiantada por autores desde meados da década de 1990, qual seja, a de uma postura ingênua diante da realidade e, além disso, de posições retrógradas e conservadoras da EF brasileira que voltaram à cena por força da lei que criou o Confef/Crefs. 


\section{Referências}

\section{ALMEIDA, A. Código de ética} profissional de educação física: analisando adesão e aplicabilidade. Dissertação (Mestrado em Educação Física) Universidade Gama Filho. Rio de Janeiro: UGF, 2002.

ANDERAÓS, M. A reorganização da formação profissional em educação física no Brasil: aspectos históricos significativos. Tese (Doutorado em Educação Física). Universidade Estadual de Campinas. Campinas: UNICAMP, 2005.

BIRK, Márcia. Interesses e disputas

no processo de formulação das Diretrizes Curriculares Nacionais para os Cursos de Graduação em Educação Física: as configurações das relações pessoais. Dissertação (Mestrado). Universidade Federal do Rio Grande do Sul. Porto Alegre: UFRGS, 2006. mimeo.

BRASIL. Lei n. ${ }^{\circ} 9649$, de 27 de Maio de 1998. Dispõe sobre a organização da Presidência da República e dos Ministérios, e dá outras providências. Diário Oficial da União. Brasília, 28 mai. 1998a.

BRASIL. Lei n. ${ }^{\circ}$ 9696, de 1 de Setembro de 1998. Dispõe sobre a regulamentação da Profissão de Educação Física e cria os respectivos Conselho Federal e Conselhos Regionais de Educação Física. Diário Oficial da União. Brasília, 2 set. 1998b.

BRASIL. Diretrizes Curriculares

Nacionais para os Cursos de Educação Física. Resolução CNE/ CES 7/2004. Diário Oficial da União. Seção 1, p. 18. Brasília, 5 abr. 2004.

CASTELLANI FILHO, L. Teses acerca da questão da regulamentação da profissão. In: CASTELLANI FILHO, L. Política educacional e educação física. Campinas: Autores Associados, 2002. p. 83-93.

COIMBRA, T.C. O reordenamento no mundo do trabalho e a precarização do trabalho do professor de educação física: mediações da mercadorização da cultura corporal. Dissertação (Mestrado em Educação). Universidade Federal Fluminense. Niterói: UFF, 2009.

COSTA, N.L. Capoeira, trabalho e educação. Dissertação (Mestrado em Educação). Universidade Federal da Bahia. Salvador: UFBA, 2007.

CRUZ, A.C.S. O embate de projetos na formação de professores de Educação Física: além da dualidade licenciaturabacharelado. Dissertação (Mestrado). Universidade Federal 
de Santa Catarina. Florianópolis: UFSC, 2009.

DRIGO, A.J. O judô: perspectiva com a regulamentação da profissão de educação física. Dissertação (Mestrado em Ciências da Motricidade). Universidade Estadual Paulista Júlio de Mesquita Filho. Rio Claro: UNESP, 2002.

EF. Revista do Confef. Programa de instrução para profissionais provisionados do CREF9-PR forma técnicos. Rio de Janeiro, n.27, março de 2008. Disponível em http://www.confef.org.br/extra/ revistaef/revista.asp?num $=27$. Acesso em 15/1/2011. p.31.

FEITOSA, W. As competências específicas do profissional de educação física: um estudo Delphi. Dissertação (Mestrado em Educação Física). Universidade Federal de Santa Catarina. Florianópolis: UFSC, 2002.

GAWRYSZEWSKI, B. Confef: organizador da mercantilização do campo da educação física. Dissertação (Mestrado em Educação). Universidade Federal do Rio de Janeiro. Rio de Janeiro: UFRJ, 2008.

MANACORDA, M.A. Marx e a pedagogia moderna. Newton Ramos-de-Oliveira (trad.). Campinas: Alínea, 2007.

MARINHO, I.P. Nova denominação para o professor de educação física: educação física, uma expressão inadequada. In: MARINHO, I.P. Coletânea de textos. Silvana Vilodre Goellner (org.). Porto Alegre: UFRGS; CBCE, 2005. p.75-93.

MARTINS, L.M. Da formação humana em Marx à crítica da pedagogia das competências. In: DUARTE, N. (org.) Crítica ao fetichismo da individualidade. Campinas: Autores Associados, 2004. p.53-73.

NOZAKI, H.T. Educação física e reordenamento no mundo do trabalho: mediações da regulamentação da profissão. 2004. Tese (Doutorado em Educação). Universidade Federal Fluminense, Niterói, 2004.

PALAFOX, G.H.M.; TERRA, D.V. Regulamentação da profissão em educação física: uma questão ideológica. Disponível em: http://mncref.sites.uol.com.br/ mncr.htm. Acesso em 12/2/2011, 16h42min.

PENNA, A.M. Sistema Confef/Crefs: a expressão do projeto dominante de formação humana na educação física. Dissertação (Mestrado em Educação). Universidade Federal Fluminense. Niterói: UFF, 2006.

SAUTCHUK, C.E. Jogando com símbolos: notas para uma antropologia da regulamentação da profissão de educação 
física. Rev.Bras.Cienc.Esporte. Campinas, v.23, n.2, jan. 2002. p.179-193.

SCHMIDT, E.M. A educação física e a regulamentação da profissão sob um olhar jurídico.

Dissertação (Mestrado em Educação). Universidade Federal de Uberlândia. Uberlândia: UFU, 2001.

SILVA, M.E.H. da. Cenas antigas em novo espetáculo: o processo de regulamentação da profissão de educação física. Dissertação (Mestrado em Educação). Universidade Federal do Ceará. Fortaleza: UFC, 2005.

SOBRINHO, J.P.deS. Formação em educação física: uma análise à luz da centralidade do trabalho. Dissertação (Mestrado em Educação). Universidade Federal do Ceará. Fortaleza: UFC, 2009.

SOFISTE, A. Profissional ou professor: interfaces de uma profissão regulamentada. Dissertação (Mestrado em Educação). Pontifícia Universidade Católica de São Paulo. São Paulo: PUC/ SP, 2007.

STEINHILBER, J. Profissional de educação física... existe? Rio de Janeiro: Sprint, 1996.

TRIVIÑOS, A.N.S. Introdução à pesquisa em ciências sociais: a pesquisa qualitativa em educação. São Paulo: Atlas, 1987.

\footnotetext{
ABSTRACT

This text aims to do a critic to the knowledge production on the subject of professional adjustment of physical education, analyzing the scientific production that defends Confef/Crefs System, on theses and dissertations published from 1998 to 2009. A survey of sources at the Bank of CAPES thesis, we selected 14 papers which deal with the subject, which are guided by favorable positions (defending Confef/Crefs) and contrary to the profession/professional adjustment of physical education. We find categories for the analysis of production and point limits philosophical, scientific and practical in knowledge production by those who defend the professional adjustment.
}

Keywords: physical education; professional adjustment; knowledge production

Recebido: março/2011

Aprovado: julho/2011. 